\title{
Marketing Clues on the Label Raise the Purchase Intention of Genetically Modified Food
}

\author{
Dan Jiang (1) and Guangling Zhang * \\ School of Economics and Management, Wuhan University, Wuhan 43000, China; danjiang@whu.edu.cn \\ * Correspondence: glzhang@whu.edu.cn
}

check for

updates

Citation: Jiang, D.; Zhang, G.

Marketing Clues on the Label Raise the Purchase Intention of Genetically Modified Food. Sustainability 2021, 13 9970. https://doi.org/10.3390/ su13179970

Academic Editor: Colin Michael Hall

Received: 25 July 2021

Accepted: 27 August 2021

Published: 6 September 2021

Publisher's Note: MDPI stays neutral with regard to jurisdictional claims in published maps and institutional affiliations.

Copyright: (c) 2021 by the authors. Licensee MDPI, Basel, Switzerland. This article is an open access article distributed under the terms and conditions of the Creative Commons Attribution (CC BY) license (https:// creativecommons.org/licenses/by/ $4.0 /)$.

\begin{abstract}
As more and more genetically modified foods (GMFs) must be labeled, adding more information to increase the willingness to buy genetically modified food has become the focus of scholars and enterprises. Most current studies have confirmed that the consumer attitudes and purchase intention toward GMFs are not good. This study aims to match consumers' different information-processing mechanisms by adding marketing information clues and regulating their purchase intentions by contradictory attitudes towards GMFs. According to the interest demands of GMFs, the marketing clue information was divided into functional information and environmental information. Through two studies, we find that consumers are more inclined to environmental information than heuristic. Functional information is more attractive to males, and the young generation prefers ecological information. Consumers with high ambivalence towards genetically modified foods are more inclined to choose environmental attribute information.
\end{abstract}

Keywords: GMFs; heuristic vs. systematic information processing; purchase intention; ambivalent attitude; information attributes; marketing cues

\section{Introduction}

The global commercialization of genetically modified organisms (GMOs) has advancing worldwide at an unprecedented speed [1]. Consumers' attitudes and behavior patterns towards genetically modified organisms will significantly impact the future of the economy [2]. According to the FAO GM Foods Platform, 191.7 million hectares of biotech crops are grown in 70 countries, and about $60 \%$ to $70 \%$ of the food on the market contains genetically modified ingredients [3,4]. However, global consumers are not optimistic about genetically modified foods (GMFs), $57 \%$ of European citizens are generally unwilling to support them [5]. GM foods use different labeling systems, as previous laws required the labeling of genetically modified organisms and their products. Operators should ensure that the labels indicate "This product contains GMOs" or "This product contains genetically modified organisms" to protect consumers' right to know and to choose. At the same time, the proportion of genetically modified food labeling information affecting purchase intention is increasing [6]. By so, the companies must label the GMO information if ingredients contain more than $5 \%$ of GMO on the US market. Chinese regulations require that as long as the product contains GMO ingredients, it must be marked on the product packaging [7]. Consumers' attitudes and purchase behaviors towards GM foods are affected by many factors, such as consumer's age, gender, education level, income and other demographic variables, their knowledge of GM foods, the recognition of scientific authority, and government (Corporate) trust, etc. [2,8-12].

Based on the investment of the Food and Agriculture Organization (FAO) and World Health Organization (WHO), for the reason of solving world hunger and agricultural production problems, GM foods will enter consumers' unavoidable purchase options [13]. As a controversial technology, GM foods not only bring environmental and functional benefits to humans but also bring human doubts about technology [4]. Manufacturer and 
sales platform are worried that consumers will refuse to buy because of GMO food labeling information regarding the strictly controlled GMO labeling system. Companies that process GMO raw materials are primarily cautious about GMO labeling information, adopting an avoidance strategy of insignificant labels. The words "This product contains genetically modified ingredients" are designed on the back of the product and displayed in tiny fonts [14]. This confidential information may reduce consumers' attention. Once consumers recognize the avoidance strategy, it will cause them to activate the system processing mode, which may lead to higher contradictory attitudes and hostile purchase intentions.

The research on food labeling information mainly focuses on four categories of healthy foods and non-healthy foods, organic foods, non-GMO foods, and GM foods, studying their composition information, pattern information, color difference, and information presentation on the purchase intention. Additionally, the brand loyalty and the research on the different information-processing mechanisms that the marketing lead content framework will initiate consumers is less involved [15-21]. The consequences of positive labeling of GM foods and the extent to which the type of information may affect consumers' attitudes towards GM foods are still largely unknown [22].

This study verified the above research content through two studies. Study 1 mainly demonstrated that the additional marketing clues would significantly increase consumers' purchase intentions compared to providing other marketing clues compared to only marking genetically modified labels. Study 2 mainly verifies that environmental cues and functional cues trigger the consumer's heuristic processing mode and system processing mode, respectively, and further explains the mechanism. Additionally, we find that different contradictory attitudes towards GM foods can regulate the main effect. In the rice selection experiment, we found that compared with functional attributes, subjects with high contradictions and high systems and high heuristic are more likely to choose genetically modified food information with environmental characteristics.

\section{Literature Review and Hypothesis}

\subsection{GM Foods Marketing Clues}

Labels are defined as "any words, details, trademarks, brand names, patterns or symbols related to food, and placed on any packaging, documents, notices accompanying or involving such foods" [21]. The product label consists of different ingredients and labeling systems. This information includes (but is not limited to) ingredient lists, nutrition labels, sustainability labels, and front-of-package labels, traffic light systems, health labels, and guidelines for daily quotas, etc. [16,23]. Consumers' attention to food labeling mainly focuses on labeling information and labeling design [24]. Consumers rely on different clues when making decisions. Some clues are directly related to product quality, which are often clues that cannot be changed, such as the taste or healthy ingredients of the product. Other clues are related to the product but not part of the product itself, such as the relevant information clues on the packaging [25]. Additional information clues will affect consumers' perceptions and behaviors regarding foods. The content of labels on foods can significantly influence the purchase decision by attracting consumers' attention and providing critical information about the product $[26,27]$. Studies have shown that food labels contain many clues to reduce risks [28]. For example, labeling sensory reminders on the label will increase consumers' evaluation of food [29] and indicate that reputation and quality attributes, such as health effects, convenience, ethical considerations, and farm animal welfare, will simplify decision-making processes [30]. The goal of food labels is to convert the inherent product and reputation attributes into searchable clues so that consumers can make choices in the fastest time with minimal cognitive effort [31]. Understanding the nutrition label on the front of the primary packaging is measured through a variety of tasks such as conceptual understanding, substantive understanding, and health inference [16]. In this article, we observe that different countries pay attention to label information. British consumers pay more attention to label information (27\%), mainly focusing on the daily intake (GDA) label and nutrition table [16]. Consumers in Germany and the United States rely more on 
packaging information and regard the labeling information on the packaging as the first choice for product selection. French consumers are more concerned about the packaging material [32].

The only difference between genetically modified food and the label of non-genetically modified food is the information prompt for genetically modified ingredients. Previous studies have focused on whether the identification of GMOs is controversial, and some scholars believe that the title of transgenic increases the risk of (ecological, environmental, and health risks, etc.) negative consumer perception, increasing its ambivalent attitude leading to a decline in the willingness to buy. Lack of appropriate labeling information and transparency and over-understanding of genetically modified knowledge may be one of the reasons that cause consumers to reject genetically modified food [33,34]. Another part of the scholars believe that the logo will increase consumer trust and increase transparency, so on the contrary, it will increase purchase intention [35].

Research on the presentation of information attributes of GM foods is divided into positive attributes and negative attributes, perceived benefits/values, perceived risks, and so on [36-39]. The benefits of labeling genetic modification will offset consumers' negative preferences for genetic modification, and the perception of benefits can offset negative perceptions related to genetic modification [39-42]. Studies have found that positive attributes have increased the acceptance of genetically modified products and impact different risk perception groups [43]. In addition to emotional value, functional value, social value, and economic value will positively affect consumers' reputation for genetic modification [44]. Because some consumers' resistance to genetically modified crops and products may be due to the lack of consumer benefits, information on potential benefits has increased consumer acceptance of GM foods [45-47].

In summary, there are two main categories of genetically modified products. One is to regard it a gain, but as a risk to avoid [48]. Genetically modified technology can provide the following nine benefits: cheaper food, low-allergen food, longer storage time, suitable for animals, less waste, fewer pests/herbicides, good for health, good for the environment, and improved flavor/enhancing taste [39]. In other words, there are three main benefits of genetic modification. The first is the benefit to human health, the second is the benefit to the environment, and the third is the benefit of improving nutrients. According to the survey, American consumers are willing to buy genetically modified properties in order to use fewer pesticides (44\%), be more environmentally friendly (31\%), consume less fat $(26 \%)$, have better taste $(21 \%)$, and be cheaper $(12 \%)$. Therefore, this article summarizes the genetically modified food information into functional attribute information and environmental information. Among them, the functional attribute information includes benefits to human health, such as more nutrients, better taste, lower allergenicity, etc.; environmental information provides for benefits to environmental protection, such as less fertilizer use, less insecticide, more drought resistance, etc.

The purpose of this study is to verify whether additional information clues will affect the purchase intention of genetically modified food. At the same time, we distinguished the types of genetically modified food leads, including functional attributes and environmental attributes. Based on the above literature review, this article proposes H1, H1a, and H1b:

H1: Compared with the legal label, the marketing clues of GM foods will affect consumers' willingness to buy.

H1a: Marketing clues with functional attributes will positively increase consumers' purchasing intentions.

H1b: Marketing leads with environmental attributes will positively increase consumers' purchasing intentions.

\subsection{Information Processing Mechanism}

How individuals process information dramatically affects the interpretation of information. Studies have confirmed that individuals tend to process systematically rather than 
heuristically [49]. The heuristic-systematic model (HSM) describes the cognitive process as systematic or heuristic [50]. System processing requires a comprehensive and analytical inspection of information related to judgments [49]. In contrast, heuristic information processing requires minimal mental effort to draw conclusions based on the model's least effort principle, relying on heuristics or non-content clues [51]. In the system model, the recipients have made considerable cognitive effort when processing information. They need to actively try to understand and evaluate the arguments of the information and evaluate its effectiveness and conclusions [52].

In contrast, in the heuristic model, the recipients have relatively little effort to judge the validity of the information. They may rely on readily available information, such as the identity of the source of the message or other non-content clues [53]. Some studies claim that the choice of these two information processing methods depends on the perceiver's motivation, ability, and judgment confidence. Suppose the recipients have higher cognitive motivation and knowledge and feel more relevant to themselves. In that case, they tend to use systematic processing, while those with lower motivation and ability mainly rely on evidence, experience, and insights to minimize their cognitive effort. However, some researchers pointed out that these two information processing modes depend on the context provided by the information $[52,54]$. First, when the importance of the task is high, and the information is clear, only systematic processing can affect attitudes. Second, when the information content contradicts the validity of the credibility heuristic, the two processing modes independently determine the mood. Finally, when the importance of the task is high, and the information content is ambiguous, both heuristics and systematic processing can affect attitudes [50,52]. Frewer et al. (1996) found that source credibility does not seem to affect news acceptance and other risk-related ideas in the dimension of food risk perception [55]. Other factors, such as the persuasiveness of the information and the type of risk, seem to play a more critical role in information processing [55].

The information context motivates people to choose different information-processing mechanisms related to the quality, accuracy, and vividness of the information and the recipient's motivation, involvement, and ability. High-quality disputes prompt the recipient to examine the information more carefully, and high-quality information may cause systematic processing [52]. When the cognitive load is tiny, the perceiver may simply use heuristic judgments, and when the cognitive load is large enough, they will start the system's processing. If the information received from the media has a high degree of personal relevance, more detailed judgments will be made if the info covers high participation areas, such as personal goals, value systems, and tools. At the same time, HSM assumes that people are cognitive scumbags, and they will avoid systematic processing because of the effort required. To enter the system mode, people must pass the "adequacy threshold," which refers to a sufficient degree of confidence that ensures they have completed their processing goals [49].

In other words, when people have no confidence in the judgments, they receive from the heuristic model, and when they want to have tremendous confidence in their decisions, they will start system pattern processing [56]. When the information generated by the system's processing contradicts the effectiveness of persuasive heuristics and accordingly strengthens or weakens the judgments driven by these heuristics, the attenuation effect seems to be noticeable.

The goal of this research is whether different information processing modes will be stimulated by different information clues, leading to different changes in purchase intentions. Based on the above inferences, we propose $\mathrm{H} 2, \mathrm{H} 2 \mathrm{a}$, and $\mathrm{H} 2 \mathrm{~b}$ :

H2: The interaction effect between the information processing mechanism and the label information type.

H2a: Compared with system processing, functional information is more likely to stimulate the heuristic processing mechanism. 
H2b: Compared with heuristic processing, environmental information is more likely to stimulate the system's processing mechanism.

\subsection{Ambivalent Attitude}

One of the main determinants of food consumption behavior is attitude [57]. In the field of ecological consumption, there are often inconsistencies between attitudes and behaviors. For example, people say that they can pay a higher premium for organic products, but this is not the case. The same story happened with environmentally friendly products. Although people expressed their concern about environmental issues, they were unwilling to buy green products. Consumers' contradictory attitudes are the positive and negative evaluations, cognition, and emotional experiences individuals simultaneously produce towards a specific object [58]. Previous studies mainly concentrated in sociology, politics, and psychology on contradictory attitudes. There is little research in consumer behavior where attitudes and behaviors are inconsistent, especially in research on GM foods with high contradictory characteristics [59].

The contradictory attitudes of consumers will be affected by external clues and are different from the fundamental social contradictions. The conflicting perspectives of consumers are at the micro level and can be changed. If they perceive ambivalent attitudes when facing choices, individuals will use information processing strategies to alleviate the cognitive load caused by ambivalent attitudes [60]. Ambiguity may lead to some conflicting intentions, options, and behaviors of frustration, and this conflict will harm the expected actions. The stronger the degree of contradiction, the weaker the stability. Attitude contradiction will adjust the relationship between attitude to behavior and behavior to conduct [61]. However, what is interesting is that this is not necessarily a positive or negative adjustment. Compared with a strong attitude, a weaker perspective is more predictive of behavior, and the variability of contradictory attitudes will increase under persuasive situations.

When an individual has a contradictory attitude towards a certain thing, what kind of information processing mode will he use to handle contradictory information? When the two modes do not produce highly contradictory information, an additive effect may occur [51], so the heuristic and system mode process can help change attitudes.

The research of Maio (1996) and Nordgren (2006) proves that highly contradictory attitudes will cause the individual's cognitive load $[62,63]$. The individual will collect more information and use the system processing model to process the information. Individuals with low contradictions are more inclined to make intuitive and straightforward decisions based on heuristic clues, which is especially common in consumer behavior. Different information processing modes will also affect the individual's choice and acceptance of information. Consumers with solid attitudes are more willing to accept information consistent with their perceptions. However, studies have found that consumers with low ambivalence attitudes will reduce their involvement and awareness of the importance of purchasing decisions when consumers use the heuristic information processing model. In contrast, consumers with high ambivalence are more suitable for adopting the system processing mode [64].

In summary, the goal of this study is to investigate whether consumers' ambivalent attitudes will adjust the matching effect of different information and dual information processing modes on purchase intentions.

H3: Contradictory attitudes will adjust the influence of information patterns on purchase intentions.

H3a: Compared with market identification information and no additional information, when there is a high contradictory attitude towards GM foods, the system's processing mode matching environmental information will increase purchase intention.

H3b: Compared with market identification information and no additional information, when there is a low ambivalence towards genetically modified food, the combination of heuristic processing mode and functional information will increase purchase intention. 
The research model diagram of this paper is in Figure 1 below:

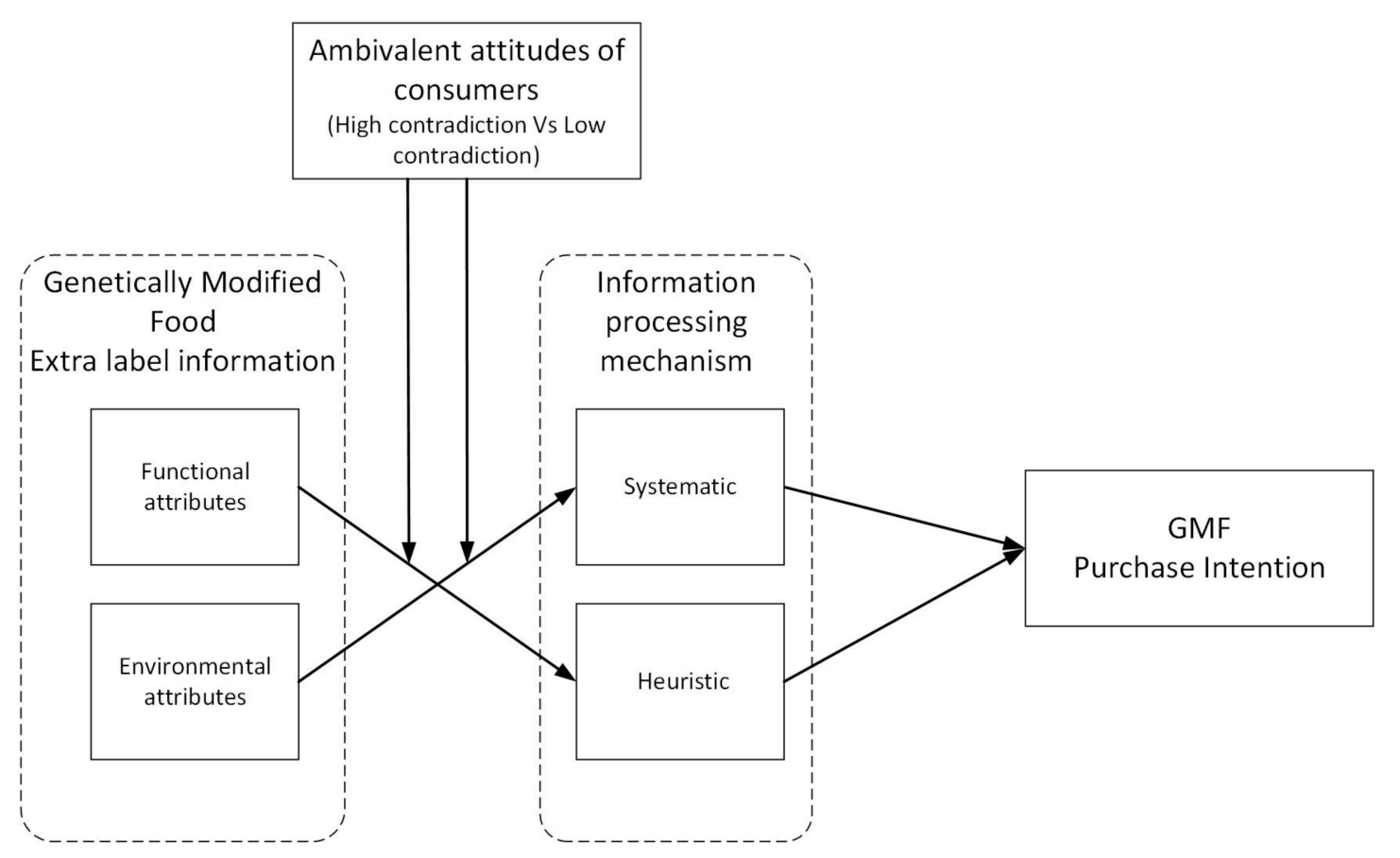

Figure 1. Research conceptual framework.

\section{Experimental Operation and Hypothesis Testing}

\subsection{Pre-Test}

According to the functional attributes and environmental attributes, 20 characteristic attributes were extracted. Subjects who were not clear about the study goal were recruited to classify the 20 typical attributes as positive, negative, and uncertain attributes. The purpose is to balance the positive and negative attributes in the additional information not to mislead the subjects, and to understand consumers' perceptions of the attributes of GM foods. The functional attributes include "the appearance is consistent with non-GMO foods," "longer storage time," "lower prices," "insect resistance," "reduction in production costs," "enhanced nutrients," "disease resistance," "better taste," "not easy to deteriorate," and "increased shelf life." Environmental attributes include "adapt to harsh environments (such as drought, cold, poor soil, etc.)," "high yield," "solve food shortages," "may have an impact on biodiversity," "reduce the use of pesticides," "reducing the labor burden of farmers," "has a certain impact on the human body," "genetically modified genes are required to be strictly labeled in my country," "attack other target organisms (such as bees, butterflies, etc.)," and "affect the growth of other crops." Figure 2 shows a comparison chart of the positive, negative, and uncertain attributes of GM foods. The top three attributes considered to be cheerful are yield, addressing food shortages, and prices. In comparison, the top three negative attributes are the impact on biodiversity and concerns that affect the human body. Uncertain attributes are the consistency of the appearance of GM foods with non-GM foods and the effect of the growth of other crops. 
Affect the growth of other crops

Attack other creatures

Not easy to deteriorate

Taste

Shelf life

Strictly marked

Affect the human body

Peasant labor burden

Pesticide use

Affect biodiversity

Solve the food shortage problem

Disease resistance

Fortified nutrients

Cost of production

Productivity

Adapt to harsh environments

Insect resistance

Price

Storge time

Appearance
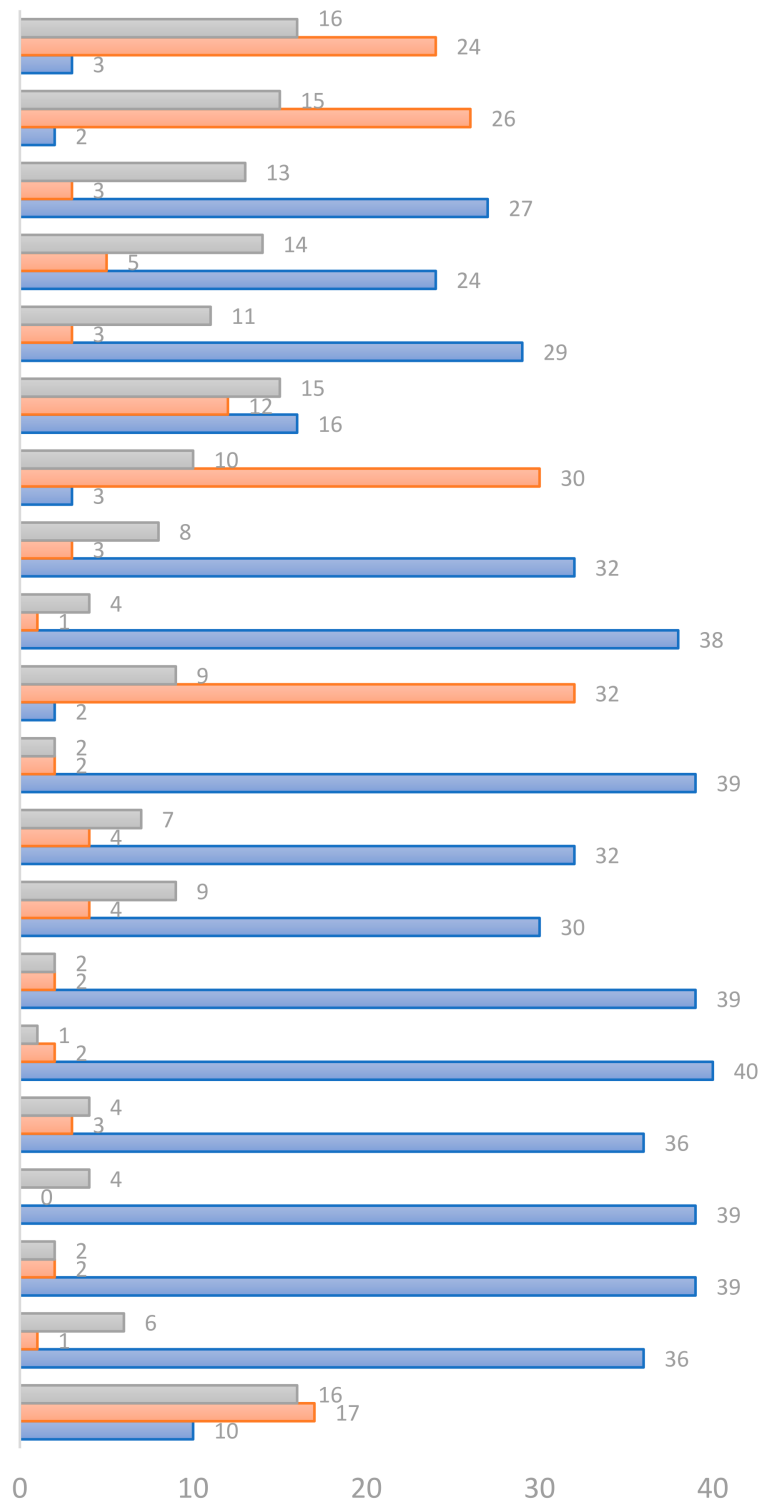

Figure 2. Graphs of positive, negative, and uncertain attributes of genetically modified genes.

At the same time, the subjects were required to classify the study target foods (14 types) that need to be used in the study into GM foods, non-transgenic foods, and uncertain (see Table 1). The purpose of the pre-test is to understand the level of Chinese consumers' understanding of GM foods sold in the existing market through this prediction, on the one hand, and to find out those foods that are misunderstood as GM foods.

Forty-three people were recruited in the pre-test, of which 55.8\% were women, and $44.2 \%$ were men. The previous test has shown that soybeans, corn, rice, tomatoes, peppers, and potatoes are often considered GM foods. It is unclear whether the genetically modified food is papaya, rape, and bell pepper.

We are not surprised to obtain this result because genetically modified food does not appear in the public eye as frequently as other common sense. People tend to classify some genetically optimized foods and foods with strange appearances as GM foods. 
Table 1. Pre-test table for genetically modified food study materials.

\begin{tabular}{|c|c|c|c|c|c|c|c|}
\hline Food Variety & $\begin{array}{l}\text { GM } \\
(\%)\end{array}$ & $\begin{array}{c}\text { NON-GM } \\
(\%)\end{array}$ & $\begin{array}{c}\text { Uncertain } \\
(\%)\end{array}$ & Food Variety & $\begin{array}{l}\text { GM } \\
(\%)\end{array}$ & $\begin{array}{c}\text { NON-GM } \\
(\%)\end{array}$ & $\begin{array}{c}\text { Uncertain } \\
(\%)\end{array}$ \\
\hline Apple & $13(30 \%)$ & $21(49 \%)$ & $9(21 \%)$ & Watermelon & $15(35 \%)$ & $16(37 \%)$ & $12(28 \%)$ \\
\hline Orange & $11(26 \%)$ & $24(56 \%)$ & $8(18 \%)$ & Bell peppers * & $22(51 \%)$ & $8(19 \%)$ & $13(30 \%)$ \\
\hline Garlic & $12(28 \%)$ & $19(44 \%)$ & $12(18 \%)$ & Potato & $19(44 \%)$ & $16(37 \%)$ & $8(19 \%)$ \\
\hline Tomato * & $26(60 \%)$ & $5(12 \%)$ & $12(28 \%)$ & Papaya & $15(35 \%)$ & $10(23 \%)$ & $18(42 \%)$ \\
\hline Soybeans *** & $40(94 \%)$ & $2(4 \%)$ & $1(2 \%)$ & Corn ** & $36(84 \%)$ & $3(7 \%)$ & $4(9 \%)$ \\
\hline Banana & $13(30 \%)$ & $18(42 \%)$ & $12(28 \%)$ & Rape & $19(44 \%)$ & $9(21 \%)$ & $15(35 \%)$ \\
\hline $\begin{array}{l}\text { Chinese } \\
\text { cabbage }\end{array}$ & $7(16 \%)$ & $25(58 \%)$ & $11(26 \%)$ & Rice $^{* *}$ & $35(81 \%)$ & $6(14 \%)$ & $2(5 \%)$ \\
\hline
\end{tabular}

Note: ${ }^{* * *}$ is considered genetically modified food by more than $90 \%$ of people, ${ }^{* *}$ is considered genetically modified food by $80-90 \%$ of people, and * is considered genetically modified food by $50-70 \%$. In this pre-test, 43 people participated in answering the questions, and their gender and age met the requirements of the pre-test. The age distribution includes subjects from 18 to 62 years old. Most of the subjects are concentrated in the range of 30-40 years old. They also happen to be one of the main purchasers.

\subsection{Study 1}

The purpose of Study 1 is to better verify the main effect of this study in a laboratory environment. It is better to distinguish between the control and control groups and conduct inter-group experiments by setting a series of questions.

\subsection{Experimental Design}

The study adopted a between-subject design of 3 pieces of information (environmental attribute information and functional attribute information and no information) by purchase intention. According to the research of Muqier et al. (2019) and Wupper et al. (2019), the study selected tomatoes with a higher consumption frequency [22,65], so we use tomatoes as experimental food. Paid recruiting subjects, all subjects will complete the trial as a test to obtain a reward by souvenir.

Participants in the functional attribute group will see a picture of a tomato and a paragraph of text: Imagine you are shopping in a supermarket. Today's shopping list includes buying fruits and vegetables, so you go to the vegetable section and see tomatoes in the supermarket. On sale, tomatoes are rich in various vitamins and taste sweet and sour. They are the vegetables you want to buy. This tomato is marked as a genetically modified tomato, and the tomato label indicates that the tomato's taste, nutrition, and storage time have been improved through genetically modified technology. After that modification, the improved tomato will taste sweet and sour, richer in nutrition, and have a longer storage time. The leading information of the environmental attribute group is consistent with that of the functional attribute group. Except for the inconsistency of label information, this tomato has been modified through genetic modification technology to improve its drought resistance, insect resistance, and disease resistance. The improved tomato is resistant to viruses, pests, and diseases. The resistance to harsh environments is equivalent to protecting the environment.

After completing the control text and picture display of the study group, the subjects were asked to fill in the following scale (see Table 2). First, ask the participant's willingness to buy questions from Dodds (1991) ("Likert Scale 7", 1 is "very unwilling," 7 is "very willing.") [66]. After completion, ask the participant's information system processing scores and risk perception questions - an item that was adapted from Feng Qiang \& Shi Yibin (2017) [67]. Finally, the subjects were asked to fill in demographic data before leaving the laboratory. 
Table 2. Measurement items of variables in Study 1.

\begin{tabular}{|c|c|c|}
\hline & Measurement & Reference \\
\hline $\begin{array}{l}\text { Attribute information (functional } \\
\text { attribute and environmental } \\
\text { protection attribute) }\end{array}$ & Study manipulation & Wuepper et al., 2019; Muqier et al., 2019 \\
\hline $\begin{array}{l}\text { System information processing } \\
\text { mechanism }\end{array}$ & $\begin{array}{l}\text { To clarify GMFs issues, I support the media } \\
\text { to provide more views and perspectives. } \\
\text { I will try my best to understand the technical } \\
\text { terms in GMFs reports. } \\
\text { Because people around me discuss GMFs } \\
\text { issues, I will try to understand these issues } \\
\text { from the news. } \\
\text { GMFs news can provide me with my views } \\
\text { on related issues. } \\
\text { When GMFs issues appear in the news, I will } \\
\text { pay attention. }\end{array}$ & Feng Qiang and Shi Yibin, 2017 \\
\hline $\begin{array}{l}\text { The heuristic system processing } \\
\text { mechanism }\end{array}$ & $\begin{array}{l}\text { For me, with experience, GMFs will not } \\
\text { bother me. } \\
\text { My information reserve is sufficient to form } \\
\text { my judgment on GMFs issues. } \\
\text { I feel that I have the ability to find and } \\
\text { experiment with GMFs-related information. }\end{array}$ & Feng Qiang and Shi Yibin, 2017 \\
\hline Risk perception (high and low) & $\begin{array}{l}\text { High: Food safety issues are becoming more } \\
\text { and more serious. } \\
\text { I am terrified of food safety issues. } \\
\text { Food safety issues will have an impact on our } \\
\text { next generation. } \\
\text { Low: The number of people affected by food } \\
\text { risk is minimal. } \\
\text { I do not care about issues related to food } \\
\quad \text { quality and safety. } \\
\text { Food safety issues will become less and less. }\end{array}$ & Feng Qiang and Shi Yibin, 2017 \\
\hline Purchase intention & Interest, possibility, and willingness to buy & Dodds, 1991 \\
\hline $\begin{array}{l}\text { Subjective knowledge of genetic } \\
\text { modification }\end{array}$ & 10 items & $\begin{array}{l}\text { According to the knowledge of } \\
\text { transgenic science of the Ministry of } \\
\text { Agriculture and Rural Affairs of the } \\
\text { People's Republic of China }\end{array}$ \\
\hline
\end{tabular}

A total of 190 subjects were recruited this time, and 20 invalid questionnaires were screened out through attention screening questions. A total of 170 subjects ( $72 \%$ of women) entered the data analysis link. Genetically modified knowledge uses 10 items to test. These 10 items are selected from government websites and related literature and then sent to experts for comment. The data show that the level of genetic modification knowledge is in the middle to the upper level. Considering that the subjects are mainly students recruited from universities, it can be inferred that the issues with higher education levels have a higher understanding of genetic modification knowledge $\left(\mathrm{M}_{\text {genetic modification knowledge }}=\right.$ $6.72, \mathrm{SD}=1.61$ ).

\subsection{Results}

First, we tested the influence of gender and age on the willingness to buy genetically modified products. T-test shows that there is no significant difference in the purchase intention of genetically modified genes between genders $(\mathrm{t}=1.318, \mathrm{~F}=0.806(\mathrm{df}=168)$, $p=0.192$ ). This conclusion is slightly different from previous studies; usually, researchers research suggests that women have a lower willingness to buy than men. According to the age distribution of the subjects, we divide the age into high and low groups. The low group is 18 to 20 years old, and the high group is 21 to 24 years old. Similar to gender, the 
T-test showed that there was no significant difference in purchase intention between the two groups $(\mathrm{t}=-0.680, \mathrm{~F}=2.752, \mathrm{df}=168, p=0.497)$. We think this may be because the study recruited mainly college students. The sample, therefore, the external validity of the data, is insufficient, so it is impossible to replicate the research on gender differences and age differences in previous studies. In addition, since college students have no real income, the variable measurement of income is not involved in this study.

After controlling for gender, age, and transgenic knowledge level, there are significant differences between the environmental attribute group, the functional attribute group, and the no message group $\left(\mathrm{M}_{\text {environment }}=5.32, \mathrm{SD}=1.19 ; \mathrm{M}_{\text {function }}=5.11, \mathrm{SD}=1.55\right.$; $\mathrm{M}_{\text {no message }}=4.52, \mathrm{SD}=1.42, p=0.008, \mathrm{R}^{2}=0.026$ ), indicating that without marking any additional information, only keeping genetically modified raw materials will significantly reduce consumers' willingness to buy, and adding explanatory information will enable consumers to increase their willingness to buy GM foods significantly. See Figure 3 bellow.

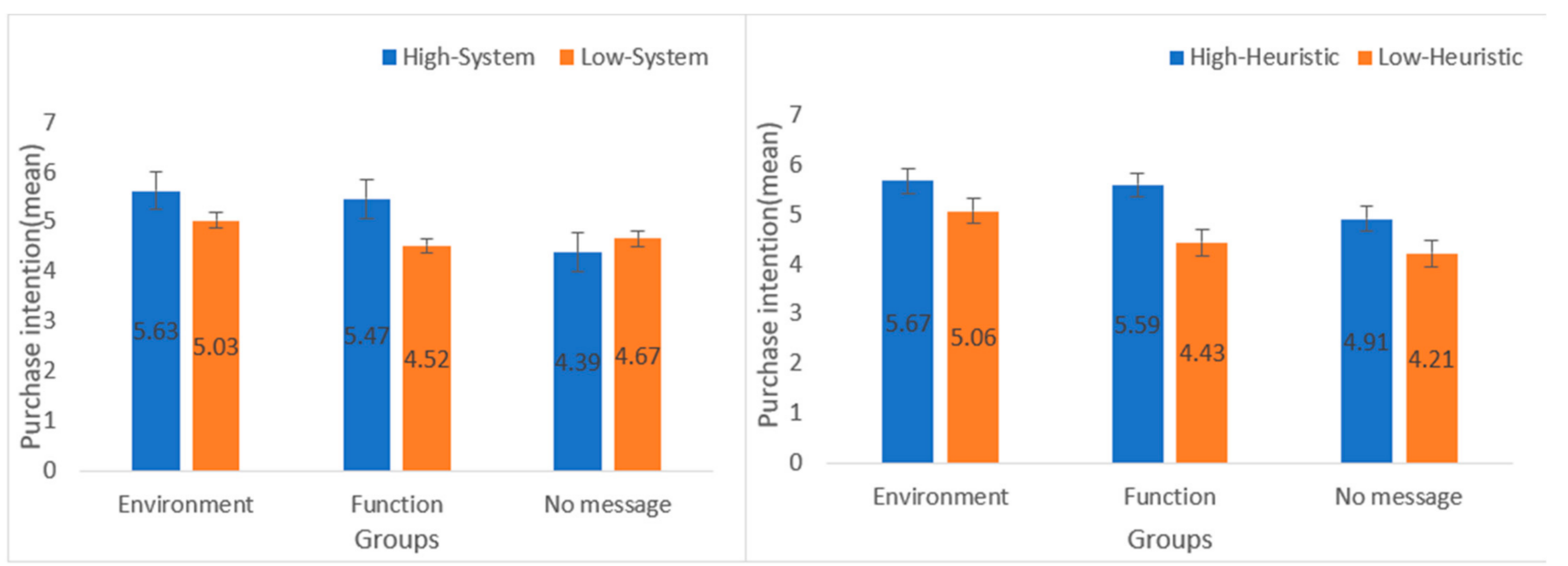

Figure 3. Interaction effect in high/low system and heuristic information processing mode of Study 1.

Interaction effect test: Use three-factor analysis of variance to evaluate the interactive influence of information (environment and function and none) by information processing mode (system and heuristic) on purchase intention. The data in each group satisfy the normal distribution and have a constant variance. The results show in the low-heuristic processing mode, there is a difference in purchase intention between the no information group and the environmental information group ( $p=0.034$ ) (see Figure 3$)$. Moreover, in the function group, the low heuristic and high heuristic subjects have a significant difference in purchasing choice. There is a considerable difference $(p=0.002)$. The functional information in GM foods is more likely to be recognized by highly heuristic and increased purchase intentions. The low heuristic and high heuristic subjects had a marginally significant effect on purchase intention $(p=0.059)$. There is a substantial difference in purchase intention in the high-system processing mode between the no additional information and environmental information groups $(p=0.046)$. The subjects' heuristic processing and system processing are grouped according to the mean in the univariate test. The average value is the high system/heuristic group, and the average value is the low system/heuristic group. It can be divided into four groups, four groups with medium-high system and low heuristic. There is a significant difference between the group $(p=0.026, \mathrm{~F}(2.158)=3.752)$ and the low system and low heuristic group $(p=0.075, \mathrm{~F}(2.158)=2.634)$.

\subsection{Discussion}

Through Study 1, it was found that compared with the genetically modified tomatoes without additional clues, providing further environmental and functional information significantly increased the participants' willingness to buy genetically modified tomatoes. 
Although there is no significant difference between the environmental attribute information and the functional attribute information, the environmental attribute information will be higher than the purchase intention of the functional attribute, and $\mathrm{H} 1, \mathrm{H} 1 \mathrm{a}$, and $\mathrm{H} 1 \mathrm{~b}$ have been verified. Different information processing modes and different information have also verified some interaction effects. Compared with environmental attribute information, functional attribute information is more suitable for awakening consumers' heuristic processing mode. $\mathrm{H} 2$ and $\mathrm{H} 2 \mathrm{a}$ have been verified. The purpose of this study is to test the main effect and the interaction effect in the model. Although the first study failed to prove $\mathrm{H} 2 \mathrm{~b}$, it demonstrates that more information can attract more consumers.

If consumers themselves have contradictory attitudes towards GM foods, will high contradictory attitudes and low contradictory attitudes play a regulatory role in purchasing intentions? Because the explanation of the environmental and functional attributes in Study 1 is not comprehensive, only a few positive attributes are involved, and the external validity is not enough. The main study product is tomato. The subjects in the study are college students, so Study 2 will explore the influence of more product choices and contradictory attitudes on the purchase intention of genetically modified food.

\subsection{Study 2}

The purpose of Study 2 is to verify further that different marketing leads information will evoke consumers' heuristic/system information processing mode and try to prove the moderating effect of consumer contradictions on purchase intention.

\subsection{Experimental Design}

Through China's largest questionnaire data collection website, we recruited 314 participants on the Internet for a fee in December 2020. After completing all the questions, each participant will receive a red envelope of RMB 5. To ensure the subjects answered the questions carefully, we inserted attention screening items at random locations in the questionnaire. Thirty-two subjects who failed the attention test were excluded from the sample size, and a total of 282 subjects entered the database.

The research design first requires the subjects to answer questions related to the information processing mode, and the system uses four question items "To fully understand the problem of genetically modified food, I think the more points I read, the better I will be. I worked hard to examine the scientific information about GM foods. I tried to understand more about GM foods. When I saw information about GM foods, I thought about it carefully." (1 is extremely non-conformed, 7 is extremely conformed, Cronbach's $\alpha=0.73$ ) for measurement. Heuristic processing uses two question items "I have accepted all the facts raised by experts without hesitation, I accept the information from the media All news content is not filtered." ( 1 being extremely non-conforming, 7 being extremely conforming, Cronbach's $\alpha=0.70$ ) for measurement.

This study does not take the way of manipulation and matching. Still, it integrates the information of each attribute into the purchase options to directly allow the participants to choose and measure their purchase intentions in repeated choices.

Assuming that the subject's preference for label information is similar in different product types, so in the selection experiment, we selected soybean milk, soybean oil, rice, tomato, and corn for the selection experiment. At present, Chinese companies adopt an evasive strategy for labeling genetically modified food labeling, assuming an insignificant display for the labeling of genetically modified food. Under the evasive marketing strategy, the market developed two different information presentations. One is that the word genetically modified does not appear in the eye-catching position of the product and is often displayed in a smaller font on the back of the product to reduce consumers' attention to genetically modified products. The second is to add additional marketing clues to the genetically modified label, that is, at the same time as the label, add a line of text to explain, "Although this product contains genetically modified ingredients, after processing, this 
product no longer contains genetically modified ingredients." In this study, we selected these two real options and placed them in the options to simulate the real label context.

A total of 10 items were measured for the subject. Participants will see a list of answers presented randomly, and items containing environmental information, functional information, market information, and unlabeled information will be asked repeatedly. The information keywords in the environmental information and function information measured in the pre-test will also appear randomly in the options. The question items start with "If you want to buy..., there are the following options in the supermarket, under the condition that all other attributes are the same", and end with "What kind of product would you buy?"

In this study, three contradictory subjective questions are used to evaluate the contradiction: "I feel more complicated about eating genetically modified food; I think the feeling of eating genetically modified food is more conflicting; I have both positive and negative comments on eating genetically modified food. "(-3 means "strongly disagree," 0 means neither disagree nor approve, +3 means "strongly agree".).

\subsection{Results}

The overall data show that women account for $41.8 \%$ of the total, with a uniform age distribution, a reasonable occupational distribution in the sample, and a monthly income of approximately RMB 3000 (see Table 3). The skewness of the four variables of gender, age, occupation, and monthly income is $0.332,0.960,1.110,0.977$, and the kurtosis is -1.903 , 0.085, -0.407, -0.097, respectively. According to West et al. (1995) and Kim (2012), when the absolute value of skewness is less than 2 , and the total value of kurtosis $(-3)$ is less than 7 , the data approximate a normal distribution [68,69]. At this time, the independent sample T-test is used to compare these four variables separately. The homogeneity of variance indicates the uniformity of the two sets of data for men and women. There is no significant difference in the total purchase intention of different genders $(F=2.106, t=-1.058, \mathrm{df}=280$, $p=0.291)$. Through further analysis, we found that there are significant differences in the choice of soy milk. The identification label (i.e., this product uses genetically modified soybeans, but the processed soymilk no longer contains genetically modified ingredients) and both the environmental label and the functional label are significantly lower than the market label $(\mathrm{F}=0.527, \mathrm{t}=2.845, \mathrm{df}=280, p=0.004)$. This is consistent with the conclusion of previous studies that people are more willing to believe in simple surface clues.

In terms of age, they are divided into three groups. The first group is Generation $\mathrm{Z}$ who are 18 to 25 years old, and the second group is Generation Y who are 26 to 40 years old. Those over 40 are classified as middle-aged and elderly consumers. One-way analysis of variance found that when the option of market labeling was provided, consumers between 18 and 25 years old had a more open vision, and they had a higher degree of acceptance of the genetic modification. Of the participants, $52.2 \%$ chose the label "No additional information on genetic modification." With the increase in age, subjects 26-40 years old are more willing to choose unlabeled products $(\mathrm{F}=25.868, \mathrm{t}=-2.979, \mathrm{df}=249, p=0.003<0.05)$, and those over 40 years old participants more prefer the market popularity label $(\mathrm{F}=5.366$, $\mathrm{t}=-6.207, \mathrm{df}=29.472, p=0.000<0.05)$ and functional attribute label $(\mathrm{F}=0.093, \mathrm{t}=2.289$, $\mathrm{df}=168, p=0.023<0.05)$. In other words, younger consumers have a higher acceptance of GM foods, while older consumers are more willing to choose unlabeled foods. When it refuses to provide additional label information for genetically modified food, it only displays "This product is genetically modified." At this time, the choice of environmental labels and functional labels has increased significantly in the three age groups. Gen. $\mathrm{Z}$ is more inclined to choose functional attributes, while consumers of other age groups have no difference between the two attributes. 
Table 3. Descriptive statistics of Study 2 sample $(\mathrm{N}=282)$.

\begin{tabular}{|c|c|c|c|c|c|}
\hline & & $\begin{array}{c}\text { Frequency } \\
(\%)\end{array}$ & Mean & SD & Variance \\
\hline \multirow{2}{*}{ Gender } & Male & $164(58.2 \%)$ & \multirow{2}{*}{1.42} & \multirow{2}{*}{0.494} & \multirow{2}{*}{0.244} \\
\hline & Female & $118(41.8 \%)$ & & & \\
\hline \multirow{6}{*}{ Age } & Under 18 & $9(3.2 \%)$ & \multirow{6}{*}{2.87} & \multirow{6}{*}{1.229} & \multirow{6}{*}{1.509} \\
\hline & $18 \sim 25$ & $150(53.2 \%)$ & & & \\
\hline & $26 \sim 30$ & $35(12.4 \%)$ & & & \\
\hline & $31 \sim 40$ & $57(20.2 \%)$ & & & \\
\hline & $41 \sim 50$ & $20(7.1 \%)$ & & & \\
\hline & 51 years old and above & $11(3.9 \%)$ & & & \\
\hline \multirow{4}{*}{ Profession } & Corporate staff & $86(30.7 \%)$ & \multirow{4}{*}{4.47} & \multirow{4}{*}{4.932} & \multirow{4}{*}{24.328} \\
\hline & Teacher & $25(8.9 \%)$ & & & \\
\hline & Student & $145(51.7 \%)$ & & & \\
\hline & Professional & $26(9.2 \%)$ & & & \\
\hline \multirow{6}{*}{ Income } & Below 2000 yuan/month & $128(45.4 \%)$ & \multirow{6}{*}{2.31} & \multirow{6}{*}{1.568} & \multirow{6}{*}{2.457} \\
\hline & 2000 4000 yuan/month & $45(16 \%)$ & & & \\
\hline & 4000 6000 yuan/month & $49(17.4 \%)$ & & & \\
\hline & 6000 8000 yuan/month & $28(9.9 \%)$ & & & \\
\hline & $8000 \sim 1000$ yuan/month & $14(5.0 \%)$ & & & \\
\hline & 10,000 yuan or more/month & $18(6.4 \%)$ & & & \\
\hline
\end{tabular}

In the occupational dimension, the environmental attribute label $(\mathrm{F}=10.463, \mathrm{t}=-3.024$, $\mathrm{df}=24.289, p=0.006<0.05)$ and the functional attribute label $(\mathrm{F}=4.174, \mathrm{t}=2.904$, $\mathrm{df}=16.207, p=0.010<0.05$ ) between the student group and the teacher group have a significant difference. However, there is no significant difference in other occupational groups, which means that teachers in the teaching occupation will prefer genetically modified food in environmental and functional labels compared with other occupations.

In terms of income, compared with a monthly income of less than 2000 yuan as a reference value, subjects with a monthly payment of 8000 to 10,000 yuan have significant differences on the unknown label $(\mathrm{F}=3.545, \mathrm{t}=-2.833, \mathrm{df}=139, p=0.005)$. That is, the higher the income group, the more preference for non-labeled genetically modified food.

When asked to what extent they fit the behavior of checking labels when buying food, $92.1 \%$ of the subjects chose the option above the median value. Most subjects would check the label and related information when buying food (Mean $=5.60, \mathrm{SD}=1.409$ ).

After single-sample T-test analysis, system processing $\left(\mathrm{M}_{\text {system }}=4.87, \mathrm{t}=-10.509\right.$, $p=0.000, \mathrm{SD}=1.13)$ and heuristic processing $\left(\mathrm{M}_{\text {heuristic }}=3.59, \mathrm{t}=-20.195, p=0.000\right.$, $\mathrm{SD}=1.66$ ) have significant differences, proving that the system and heuristic measurement is successful.

We use multiple logistic regression to analyze data. When dealing with multiple logistic regression, it is necessary to diagnose the collinearity of all the independent variables involved. If there is a high correlation between the independent variables, it will lead to partial regression coefficients of the independent variables. Infinite solutions or no solutions make it difficult to obtain an accurate prediction model. It is generally believed that when the VIF value is greater than or equal to 10, it is considered that there is high multicollinearity between the independent variables of the model. The correlation between contradictory attitudes, systematic processing, and heuristic processing is high. Gender, age, and income are used as control variables. The dependent variable is purchase intention. It can be seen from Table 4 that the variance expansion factor of each explanatory variable 
is minimal and does not exceed the extreme value. It can be considered that there is no problem of multicollinearity among the variables.

Table 4. Diagnosis of multicollinearity.

\begin{tabular}{|c|c|c|c|c|c|c|c|c|}
\hline & \multirow[t]{2}{*}{ Model } & \multicolumn{2}{|c|}{$\begin{array}{l}\text { Unstandardized } \\
\text { Coefficient }\end{array}$} & \multirow{2}{*}{$\frac{\begin{array}{c}\text { Standardization } \\
\text { Coefficient }\end{array}}{\text { Beta }}$} & \multirow[t]{2}{*}{$\mathbf{t}$} & \multirow[t]{2}{*}{$p$} & \multicolumn{2}{|c|}{ Collinearity Statistics } \\
\hline & & B & SE & & & & Tolerance & VIF \\
\hline \multirow{4}{*}{1} & Constant & 18.314 & 0.830 & & 22.063 & $0.000^{* * *}$ & & \\
\hline & Ambivalent attitude & 0.223 & 0.109 & 0.125 & 2.037 & $0.043^{* *}$ & 0.937 & 1.067 \\
\hline & Heuristic processing & -0.098 & 0.088 & -0.067 & -1.114 & 0.266 & 0.968 & 1.033 \\
\hline & Systematic processing & 0.016 & 0.126 & 0.008 & 0.125 & 0.901 & 0.945 & 1.058 \\
\hline \multirow{8}{*}{2} & Constant & 18.168 & 0.909 & & 19.976 & $0.000 * * *$ & & \\
\hline & Ambivalent attitude & 0.199 & 0.116 & 0.112 & 1.718 & 0.087 & 0.841 & 1.188 \\
\hline & Heuristic processing & -0.110 & 0.089 & -0.075 & -01.229 & 0.220 & 0.949 & 1.054 \\
\hline & Systematic processing & 0.014 & 0.127 & 0.007 & 0.107 & 0.915 & 0.935 & 1.069 \\
\hline & Gender & 0.201 & 0.318 & 0.041 & 0.632 & 0.528 & 0.851 & 1.175 \\
\hline & Age & -0.084 & 0.174 & -0.043 & -0.486 & 0.628 & 0.460 & 2.175 \\
\hline & Profession & 0.018 & 0.039 & 0.036 & 0.453 & 0.651 & 0.559 & 1.790 \\
\hline & Monthly income & 0.084 & 0.119 & 0.054 & 0.699 & 0.485 & 0.598 & 1.672 \\
\hline
\end{tabular}

DV: total purchase intention ${ }^{* *} p<0.01 ; * * *<0.001$.

Higher than the mean value is a high contradictory attitude, the grouping code is 1 , and the group lower than the average is a common contradictory attitude of which code is $0\left(\mathrm{M}_{\text {contradictory attitude }}=4.90, \mathrm{SD}=1.36\right)$. The system processing and heuristic processing are coded similarly $\left(\mathrm{M}_{\text {systematic }}=5.75, \mathrm{SD}=1.18, \mathrm{M}_{\text {heuristic }}=3.60, \mathrm{SD}=1.66\right)$.

For the selection preference of soybean milk, first, use the chi-square test to test the preferences of labeled genetically modified soybeans (without additional information) and soybeans, respectively. The results show that the subjects' choices do not obey the equal frequency distribution. That is, the subjects' preferences for genetically modified soybeans and soybeans have significant differences $\left(\chi^{2}=5.121\right.$, $\left.\mathrm{df}=1, p=0.024\right)$. When faced with three choices, the chi-square test showed significant differences between functional attributes, environmental attributes, and market identification information $\left(\chi^{2}=12.511\right.$, $\mathrm{df}=2, p=0.002)$, among which 122 people chose the market identification $(43.3 \%), 80$ people with environmental attributes $(28.4 \%)$, and 80 people with functional features $(28.4 \%)$. That repeats the conclusion of Study 1 and proved H1, H1a, and H1b.

Then, a binary logistic regression is performed on the two items of soy milk purchase intention. Cox and Snell $\mathrm{R}^{2}=0.047$ and Nagelkerke $\mathrm{R}^{2}=0.063$ indicate that the model fits the data well, and $61 \%$ of the data are correctly classified. The model shows that heuristic information has no significant impact on purchase intention, while contradictory attitudes and system processing have a significant effect on purchase intention $(\operatorname{Exp}(B)$ contradictory attitude $=1.285, p=0.013 ; \operatorname{Exp}(B)$ system $=0.726, p=0.010)$, which proved that part of the conclusions of $\mathrm{H} 3 \mathrm{a}$ and $\mathrm{H} 3 \mathrm{~b}$ is supported, because only in the high system and high heuristic processing mode will significant findings be obtained. Then, we performed multiple logistic regression on the soymilk items with three options. According to the conclusion of Study 1, high-system and high-inspiring subjects and contradictory attitudes were screened out to interactively verify the influence of the main effect on the purchase intention of the three categories, and the model was fitted. Good (Pearson $\chi^{2}=44.489, \mathrm{df}=54, p=0.001$ ) and the overall prediction rate is $57.4 \%$. Compared with environmental attributes and functional attributes, male customers prefer the functional attribute information of genetically modified food labels $(\operatorname{Exp}(B)=0.476, p=0.027)$, and 
18 to 40-year-old customers prefer the environmental information of genetically modified food labels $(\operatorname{Exp}(B))=63,480,002.7, p=0.000)$. There is no difference in preference for different information between high and low ambivalent attitudes.

Soybean oil selection preference: Multiple logistic regression shows that the model fits well $\left(\chi^{2}=111.116, \mathrm{df}=54, p=0.000\right)$. Low systems and low heuristics consumers prefer external messages more than the market label $(\operatorname{Exp}(B)=6.004, p=0.000)$, the prediction rate of the model reached $57.4 \%$. The number of people selected by the market label was $115(40.8 \%), 83(29.4 \%)$ for environmental attributes, and $84(29.8 \%)$ for functional features. There is no difference in preference for information between high and low ambivalent attitudes.

Rice selection preference: Different from the selection set of soybean oil and soy milk, the selection preference of rice is to compare the functional attributes and environmental attributes with the selection of only labeling genetically modified ingredients without additional information. In the first question, only 13 people $(4.6 \%)$ chose no further information, 106 people (37.6\%) with environmental attributes, and 163 people $(57.8 \%)$ with functional features. Multivariate logistic regression results showed that the model prediction percentage was $57.8 \%$. Compared with functional attributes, subjects with high contradictions, high systems, and high heuristics are more likely to choose genetically modified food information with environmental features $(\operatorname{Exp}(B)=28,394,872.37, p=0.000)$. This significant effect was not observed in subjects with low contradictions, low systems, and low heuristics $(\operatorname{Exp}(\mathrm{B})=2.720, p=0.239)$.

It is worth noting that the above effects did not appear in the purchase of tomatoes and corn. When only two information choices are presented, there is no significant difference between environmental attributes and functional attributes, and the degree of contradiction does not affect the main effect. In conclusion, our expected contradictory attitude did not regulate all matching relationships, and H3a was only partially verified in this study. Under low contradictory attitude, neither environmental information clue nor functional information clue has a significant impact on purchase intention.

\subsection{Discussion}

Through Study 2, we found that subjects with low contradictions, low systems, and low heuristics were not sensitive to the two kinds of additional information. This also verifies the conclusions of predecessors on genetically modified food. In other words, consumers who generally do not have a particularly ambivalent attitude towards GM foods will not mind whether the information they provide is environmentally friendly or functionally improved. They may be affected by other factors, such as price, and choose GM foods. In our research, although the text suggests that all study stimuli have the same price, we have to admit that the price factor has a huge motivation to change consumer attitudes and behaviors. Secondly, we found that consumers with high contradictions, high systems, and high inspirations prefer environmental information and are supported by data in both rice and soy milk.

\section{Discussion}

In the actual situation, many other alternative explanations and interference variables will affect consumers' purchase intentions. For example, consumers ignore the label of genetically modified food. After all, domestic food labels are mostly set on the back of the product, and to avoid, consumers have the psychology of rejection of genetically modified technology. Most companies choose to reduce consumer attention as much as possible to focus on product label information. Through two studies, we tried to prove that even in the case of the positive labeling of genetically modified foods, simply adding marketing leads can increase consumers' willingness to buy. These conclusions replicate the research of Wuepper et al. (2019) and Guo et al. (2020) and increase the different national samples of this type of research. At the same time, we tried to consider how different types of genetically modified information cues, such as environmental attribute cues and functional 
attribute cues, can activate different information-processing mechanisms. This further expands the research of information-processing mechanisms in the field of risk.

We show that older people will be more concerned about the impact of genetically modified agricultural products on the environment and their health. The younger group believes more in science, and men have a better understanding of genetically modified products than women and are more willing to participate in discussions and make suggestions. In other words, those millennials who are more educated and understand biotechnology are more inclined to buy GM foods [70]. Compared with non-millennials, they believe that there are fewer risks and fewer security issues. In addition, compared with female millennials, male millennials are more willing to buy genetically modified products and are more supportive of encouraging genetically modified technologies. In addition, the level of income is also a key factor for consumers to choose GM foods and non-GMO foods. From the market experience, GM foods are about $20 \%$ cheaper than non-GM foods because of their higher yields and low planting costs.

Even in highly contradictory consumption, it may be straightforward to reverse their attitudes and behaviors, just by providing additional information on environmentally friendly attributes. In addition, the data also show that the concealment of GM foods in the existing Chinese market is not advisable, because the hidden labels are deceiving themselves. Because once consumers find the genetically modified tags without additional explanation information, they will have a negative impression of the product and brand. That means a better approach is to positively label genetically modified information on GM foods and provide functionally friendly or environmentally friendly information.

\subsection{Theoretical Contribution}

The literature on the impact of information processing patterns and ambivalent attitudes on accepting GM foods is unclear. Some studies have found positive relationships, and some have found negative associations [22,54]. In the face of additional marketing information for GM foods, this study confirms that, compared with the hidden expression of genetically modified ingredients, direct interpretation of additional information for GM foods will increase the willingness to buy GM foods. Although the level of contradiction cannot fully explain the differences in purchase intention of all study products, the level of denial regulates not all foods. It may be because consumers have different perceptions of whether tomatoes and corn are GM foods compared to soybeans and rice, which results in insignificant effects. Previous studies have also pointed out the difference in the frequency of consumption, whether the person who releases the information is trusted, whether it is authoritative, and other factors that will cause this conclusion [2]. Through a preliminary study and two experiments, this research further expands the research of the information processing model in the processing of genetically modified food label information. Compared with the system activation, the functional information on the surface can activate the consumer's heuristic processing mechanism.

In addition, from the attitude theory, it is proposed that consumers with high contradictions are consumers who can adjust the high system and high heuristic processing mechanism to purchase different label information. In addition to further verifying that high ambivalence is evidence that can be persuaded, it also provides new interactive evidence.

\subsection{Practical Contribution}

The paramount practical significance of this research is that companies can consider adding additional explanatory information to GM foods through the distribution of high and low contradictory groups of different foods. Selective environmental attribute information and functional attribute information to increase consumers' willingness to buy may positively improve corporate social responsibility and environmental protection image. In addition, the measurement of objective knowledge about genetic modification also reflects that mainstream consumers now generally have a relatively high degree of knowledge of 
genetic modification. It is consistent with the previous conclusion that the more knowledge the customer has, the more they agree on genetically modified food. Previous studies have shown that the more consumers hate genetically modified products, the less they will change their minds. This research indicates that the current domestic consumers no longer "talk about changing colors." They have consented to the market for genetically modified food to exist. Additionally, a considerable number of consumers support genetic modification. Once they are given additional information that is beneficial to the environment (altruistic stimulation) or function (individualism stimulation), they will increase their willingness to choose GM foods.

\subsection{Future Research}

One direction of future research can be to consider further research from the main body of the information publisher, whether the authoritative main body of the information is the enterprise or the government, and whether the consumption frequency is high or low is included in the regression model. The other direction is whether the presentation form of information clues is language or image. Excessive information content will affect consumers' choices, especially in the online shopping environment. Because physical prompts (touch/smell) are not available, consumers will rely more on product-related clues to make purchasing decisions, such as price, seller reputation, historical sales, online reviews, etc. In this study, information is divided into environmental attributes and functional attributes. To present the information in a one-sentence offline study is practical to improve purchase intention, but it has not been verified online. At the same time, we did not consider the authoritative interpretation of label information during the study manipulation, that is, to provide consumers with context of background clues, which may have an impact on consumers' processing of information.

Finally, the information on why high-contradiction consumers chose environmental attributes while rejecting GM foods is worthy of further discussion. This may be due to human sacrifice or threat theory that has played a role. Future research can do more on the psychological mechanism of genetically modified food choice willingness.

Author Contributions: All authors have contributed substantially to the entire work reported. Conceptualization, G.Z.; methodology, D.J.; writing-D.J.; writing-review and editing,; supervision, G.Z.; writing-review and editing-D.J. and G.Z. All authors have read and agreed to the published version of the manuscript.

Funding: This research was funded by the major project of The National Natural Science Foundation of China, grant number 71832010 and The general project of the Hubei Provincial Social Science Foundation of China, grant number 2016089.

Institutional Review Board Statement: Not applicable.

Informed Consent Statement: Not applicable.

Data Availability Statement: Not applicable.

Conflicts of Interest: The authors declare no conflict of interest.

\section{References}

1. Smith, P.J.; Jamiyansuren, B.; Kitsuki, A.; Yang, J.; Lee, J. Determinants of comparative advantage in GMO intensive industries. World Trade Rev. 2018, 17, 427-449. [CrossRef]

2. Hunt, K.P.; Wald, D.M. The role of scientific source credibility and goodwill in public skepticism toward GM foods. Environ. Commun. 2020, 14, 971-986. [CrossRef]

3. ISAAA. ISAAA 2019 Accomplishment Report. 2020. Available online: https:/ /www.isaaa.org/ (accessed on 1 December 2020).

4. The Food and Agriculture Organization of the United Nations. FAO GM Foods Platform. FAO: Rome, Italy, 2021. Available online: http:/ / www.fao.org/food/food-safety-quality/gm-foods-platform/en/ (accessed on 1 December 2020).

5. Pew Research Center. Public Opinion about Genetically Modified Foods and Trust in Scientists Connected with these Foods; Pew Research Center: Washington, DC, USA. Available online: https://www.pewresearch.org/science/2016/12/01/public-opinion-aboutgenetically-modified-foods-and-trust-in-scientists-connected-with-these-foods / (accessed on 1 December 2020). 
6. Wunderlich, S.; Gatto, K.A. Consumer perception of genetically modified organisms and sources of information. Adv. Nutr. 2015, 6, 842-851. [CrossRef] [PubMed]

7. Ministry of Agriculture of the People's Republic of China. Administrative Measures for the Labeling of Agricultural Genetically Modified Organisms (Revised Edition); Ministry of Agriculture Order No. 8: Beijing, China, 2017.

8. Bovay, J.; Alston, J.M. GMO food labels in the United States: Economic implications of the new law. Food Policy 2018, 78, 14-25. [CrossRef]

9. Davis, V. GMO Labeling Makes Public More Likely to Trust Food Companies. Science. Available online: https://www.science. org/news/2018/06/gmo-labeling-makes-public-more-likely-trust-food-companies (accessed on 28 June 2018).

10. Kerr, J.R.; Wilson, M.S. Changes in perceived scientific consensus shift beliefs about climate change and GM food safety. PLoS ONE 2018, 13, e0200295. [CrossRef] [PubMed]

11. Wilson, G.A.; Zhang, D.D. The marketing of genetically modified food with direct and indirect consumer benefits: An analysis of willingness to pay. J. Commer. Biotechnol. 2018, 24, 27-39. [CrossRef]

12. Rose, K.M.; Howell, E.L.; Su, L.Y.F.; Xenos, M.A.; Brossard, D.; Scheufele, D.A. Distinguishing scientific knowledge: The impact of different measures of knowledge on genetically modified food attitudes. Public Underst. Sci. 2019, 28, 449-467. [CrossRef]

13. WHO. FAO/WHO Call for More International Collaboration to Solve Food Safety and Quality Problems. Available online: https: / / www.who.int/news/item/02-07-2001-fao-who-call-for-more-international-collaboration-to-solve-food-safetyand-quality-problems (accessed on 19 August 2021).

14. National Food Quality Supervision and Inspection Center. Know More-Genetically Modified Food; Food and Environmental Hygiene Department: Beijing, China. Available online: http:/ / www.cfda.com.cn/NewsDetail.aspx?id=133825 (accessed on 20 June 2016).

15. Teisl, M.F.; Radas, S.; Roe, B. Struggles in optimal labelling: How different consumers react to various labels for genetically modified foods. Int. J. Consum. Stud. 2008, 32, 447-456. [CrossRef]

16. Grunert, K.G.; Wills, J.M.; Fernández-Celemín, L. Nutrition knowledge, and use and understanding of nutrition information on food labels among consumers in the UK. Appetite 2010, 55, 177-189. [CrossRef]

17. Lee, J.-S.; Yoo, S.-H. Willingness to pay for GMO labeling policies: The case of Korea. J. Food Saf. 2011, 31, 160-168. [CrossRef]

18. Amaru, S. A natural compromise: A moderate solution to the GMO \& "natural" labeling disputes. Food Drug Law J. 2014, 69, 575. [PubMed]

19. Nunziato, T. You say tomato, i say Solanum Lycopersicum containing beta-ionone and phenylacetaldehyde: An analysis of Connecticut's GMO labeling legislation. Food Drug Law J. 2014, 69, 471.

20. Schouteten, J.J.; Gellynck, X.; De Steur, H. Consumers' perceptions of GM-free labelled foods: A sensory experiment. Int. J. Consum. Stud. 2018, 42, 347-357. [CrossRef]

21. Tanner, S.A.; McCarthy, M.B.; O'Reilly, S.J. Exploring the roles of motivation and cognition in label-usage using a combined eye-tracking and retrospective think aloud approach. Appetite 2019, 135, 146-158. [CrossRef]

22. Wuepper, D.; Wree, P.; Ardali, G. Does information change German consumers' attitudes about genetically modified food? Eur. Rev. Agric. Econ. 2019, 46, 53-78. [CrossRef]

23. Bialkova, S.; van Trijp, H.C.M. An efficient methodology for assessing attention to and effect of nutrition information displayed front-of-pack. Food Qual. Prefer. 2011, 22, 592-601. [CrossRef]

24. Singhal, N. A study of consumer behaviour towards genetically modified foods and the moderating effects of health consciousness. Vision J. Bus. Perspect. 2018, 22, 306-315. [CrossRef]

25. Maison, D.; Marchlewska, M.; Syarifah, D.; Zein, R.A.; Purba, H.P. Explicit versus implicit "Halal" information: Influence of the Halal Label and the country-of-origin information on product perceptions in Indonesia. Front. Psychol 2018, 9, 382-389. [CrossRef]

26. Ares, G.; Deliza, R. Studying the influence of package shape and colour on consumer expectations of milk desserts using word association and conjoint analysis. Food Qual. Prefer. 2010, 21, 930-937. [CrossRef]

27. Deliza, R.; Macfie, H.; Hedderley, D. Information affects consumer assessment of sweet and bitter solutions. J. Food Sci. 2010, 61, 1080-1084. [CrossRef]

28. Brach, S.; Walsh, G.; Shaw, D. Sustainable consumption and third-party certification labels: Consumers' perceptions and reactions. Eur. Manag. J. 2017, 36, 254-265. [CrossRef]

29. Chambers, L.; Ells, H.; Yeomans, M.R. Can the satiating power of a high energy beverage be improved by manipulating sensory characteristics and label information? Food Qual. Prefer. 2013, 28, 271-278. [CrossRef]

30. Pakseresht, A.; McFadden, B.R.; Lagerkvist, C.J. Consumer acceptance of food biotechnology based on policy context and upstream acceptance: Evidence from an artefactual field experiment. Eur. Rev. Agric. Econ. 2017, 44, 757-780. [CrossRef]

31. Anders, S.; Schroeter, C. The impact of nutritional supplement intake on diet behavior and obesity outcomes. Agric. Appl. Econ. Assoc. 2017, 12, 10-27. [CrossRef] [PubMed]

32. Herbes, C.; Beuthner, C.; Ramme, I. How green is your packaging-A comparative international study of cues consumers use to recognize environmentally friendly packaging. Int. J. Consum. Stud. 2020, 44, 258-271. [CrossRef]

33. Lefebvre, S.; Cook, L.A.; Griffiths, M.A. Consumer perceptions of genetically modified foods: A mixed-method approach. J. Consum. Mark. 2019, 36, 113-123. [CrossRef]

34. Lu, B.; Han, L. GMO risk management: Review and reference of foreign experience. Foreign Theor. Trends 2017, 8, 119-126. 
35. Popp, J.; Oláh, J.; Fári, M.; Balogh, P.; Lakner, Z. The GM-regulation game-The case of Hungary. Int. Food Agribus. Manag. Rev. 2018, 21, 945-968. [CrossRef]

36. James, S.; Burton, M. Consumer preferences for GM food and other attributes of the food system. Aust. J. Agric. Resour. Economics 2003, 47, 501-518. [CrossRef]

37. Miles, S.; Hafner, C.; Bolhaar, S.; Mancebo, E.G.; Fernández Rivas, M.; Knulst, A.; Hoffmann Sommergruber, K. Attitudes towards genetically modified food with a specific consumer benefit in food allergic consumers and non-food allergic consumers. J. Risk Res. 2006, 9, 801-813. [CrossRef]

38. Frewer, L.J.; Howard, C.; Shepherd, R. Public concerns in the United Kingdom about general and specific applications of genetic engineering: Risk, benefit, and ethics. Sci. Technol. Hum. Values 1997, 22, 98-124. [CrossRef]

39. Gaskell, G.; Allum, N.; Wagner, W.; Kronberger, N.; Torgersen, H.; Hampel, J.; Bardes, J. GM foods and the misperception of risk perception. Risk Anal. 2010, 24, 185-194. [CrossRef] [PubMed]

40. Moon, W.; Balasubramanian, S.K. Willingness to pay for non-biotech foods in the U.S. and U.K. J. Consum. Aff. 2003, 37, 317-339. [CrossRef]

41. Zhang, M.; Hu, W.; Chen, C.; Chen, L.; Zhan, J. Influence of information content credibility on consumer acceptance of genetically modified foods: A case study of Jiangsu Province. J. Stat. Inf. 2017, 1, 122-128.

42. Pei, W.; Zang, M. Research on the impact of consumer perceived value on the purchase intention of genetically modified food-Take the reputation of genetically modified soybean oil as the modulating variable. Jiangsu Agric. Sci. 2017, 7, 325-330.

43. Emberger-Klein, A.; Zapilko, M.; Menrad, K. Consumers' preference heterogeneity for GM and organic food products in Germany. Agribusiness 2016, 32, 203-221. [CrossRef]

44. Brown, J.L.; Ping, Y. Consumer perception of risk associated with eating genetically engineered soybeans is less in the presence of a perceived consumer benefit. J. Am. Diet. Assoc. 2003, 103, 208-214. [CrossRef]

45. Lusk, J.L.; House, L.O.; Valli, C.; Jaeger, S.R.; Moore, M.; Morrow, J.L.; Traill, W.B. Effect of information about benefits of biotechnology on consumer acceptance of genetically modified food: Evidence from experimental auctions in the United States, England, and France. Eur. Rev. Agric. Econ. 2004, 31, 179-204. [CrossRef]

46. Phillips, D.M.; Hallman, W.K. Consumer risk perceptions and marketing strategy: The case of genetically modified food. Psychol. Mark. 2013, 30, 739-748. [CrossRef]

47. Chaiken, S. Heuristic and systematic information processing within and beyond the persuasion context. Unintended Thought 1989, 19, 212-252.

48. Chaiken, S.; Maheswaran, D. Heuristic processing can bias systematic processing: Effects of source credibility, argument ambiguity, and task importance on attitude judgment. J. Personal. Soc. Psychol. 1994, 66, 460-473. [CrossRef]

49. Bohner, G.; Chaiken, S.; Hunyadi, P. The role of mood and message ambiguity in the interplay of heuristic and systematic processing. Eur. J. Soc. Psychol. 2010, 24, 207-221. [CrossRef]

50. Ryu, Y.; Kim, S. Testing the heuristic/systematic information-processing model (HSM) on the perception of risk after the Fukushima nuclear accidents. J. Risk Res. 2014, 18, 840-859. [CrossRef]

51. Pratap, J.S.; Durairaj, M. Motivated reasoning: A depth-of-processing perspective. J. Consum. Res. 2000, 26, 358-371.

52. Guo, Q.; Yao, N.; Zhu, W. How consumers' perception and information processing affect their acceptance of genetically modified foods in China: A risk communication perspective. Food Res. Int. 2020, 137, 109518. [CrossRef] [PubMed]

53. Frewer, L.J.; Howard, C.; Hedderley, D.; Shepherd, R. What determines trust in information about food related risks? Risk Anal. 1996, 16, 473-486. [CrossRef]

54. Kim, J.; Paek, H.-J. Information processing of genetically modified food messages under different motives: An adaptation of the multiple-motive heuristic-systematic model. Risk Anal. 2010, 29, 1793-1806. [CrossRef] [PubMed]

55. Shepherd, R.; Raats, M.M. Attitudes and Beliefs in Food Habits. In Food Choice, Acceptance and Consumption; Springer: Boston, MA, USA, 1996; pp. 346-364.

56. Feng, X.; Huang, M.; Zhang, Y. Ambivalent consumer's attitude more easily to be influenced? The differences of attitudinal components changes among ambivalent consumers. Nankai Bus. Rev. 2013, 1, 92-101.

57. Wang, D.; Yao, T.; Yao, F. To Buy or not to buy?A study on ecological buying intention in perspective of ambivalent attitude. Nankai Bus. Rev. 2015, 18, 136-146.

58. Xu, Z.-F.; Xi, J.-Z. Attitudinal ambivalence: Origins and coping strategies. Adv. Psychol. Sci. 2018, 26, 331-343. [CrossRef]

59. Jonas, K.; Broemer, P.; Diehl, M. Attitudinal ambivalence. Eur. Rev. Soc. Psychol. 2000, 11, 35-74. [CrossRef]

60. Maio, G.R.; Bell, D.W.; Esses, V.M. Ambivalence and persuasion: The processing of messages about immigrant groups. J. Exp. Soc. Psychol. 1996, 32, 513-536. [CrossRef] [PubMed]

61. Dijksterhuis, A.; Bos, M.W.; Nordgren, L.F.; Van Baaren, R.B. On making the right choice: The deliberation-without-attention effect. Science 2006, 311, 1005-1007. [CrossRef] [PubMed]

62. Lin, R.; Yang, Y.; Xia, C. The effect of ambivalent attitude on selective exposure-the moderated role of elaboration. China Bus. Market. 2020, 34, 51-62.

63. Mu, Q.; Li, H.; Zhao, Z.; Kong, F.; Cui, Y.; Liu, G.; Li, D. The diet and diet structure of Beijing residents. Food Nutr. China 2019, 25, 76-78+72.

64. Dodds, W.B.; Monroe, K.B.; Grewal, D. Effects of price, brand, and store information on buyers' product evaluations. J. Mark. Res. 1991, 28, 307-319. 
65. Feng, Q.; Shi, Y. The impact of media use on individuals' risk perception of food safety:An empirical study. J. Commun. Rev. 2017, 70, 113-121. [CrossRef]

66. West, S.G.; Finch, J.F.; Curran, P.J. Structural Equation Models with Nonnormal Variables: Problems and Remedies; Sage Publication, Inc.: Thousand Oaks, CA, USA, 1995.

67. Kim, R.B. Consumer attitude of risk and benefits toward genetically modified (GM) foods in South Korea: Implications for food policy. Eng. Econ. 2012, 23, 189-199. [CrossRef]

68. Kajale, D.B.; Becker, T.C. Factors influencing young consumers' acceptance of genetically modified food in India. J. Food Prod. Mark. 2015, 21, 461-481. [CrossRef]

69. Öz, B.; Unsal, F.; Movassaghi, H. Consumer attitudes toward genetically modified food in the United States: Are Millennials different? J. Transnatl. Manag. 2018, 23, 3-21. [CrossRef]

70. Pham, N.; Mandel, N. What influences consumer evaluation of genetically modified foods? J. Public Policy Mark. 2019, 38, $263-279$. [CrossRef] 